\title{
Working Characteristics of a Mechanical Insufflation-Exsufflation Device
}

\author{
Yan Shi, ${ }^{1,2}$ Shuai Ren, ${ }^{1}$ Maolin Cai, ${ }^{1}$ and Weiqing $X u^{1}$ \\ ${ }^{1}$ School of Automation Science and Electrical Engineering, Beihang University, Beijing 100191, China \\ ${ }^{2}$ The State Key Laboratory of Fluid Power Transmission and Control, Zhejiang University, Hangzhou 310058, China
}

Correspondence should be addressed to Weiqing Xu; xuweiqing2010@gmail.com

Received 9 May 2014; Accepted 14 July 2014; Published 23 July 2014

Academic Editor: Yunhua Li

Copyright (C) 2014 Yan Shi et al. This is an open access article distributed under the Creative Commons Attribution License, which permits unrestricted use, distribution, and reproduction in any medium, provided the original work is properly cited.

\begin{abstract}
Secretions of ventilated patients must be cleared efficiently and timely; to improve the secretion clearance efficiency of an insufflation-exsufflation device (IL-IE device) and lay a foundation for the optimization of the IL-IE device, a mathematical model of the ventilation system with the IL-IE device is set up. Through the experimental and simulation research on the ventilation system, it can be concluded that, firstly, the mathematical model is proved to be authentic and reliable. Secondly, with the deposition of secretion or an increase in the respiratory compliance, the peak exsufflation airflow may be reduced. Thirdly, with a decrease in the suction pressure, the peak exsufflation airflow of the ventilated lung may rise proportionally, but the minimum pressure in the ventilated lung may descend proportionally. To improve the efficiency of the secretion clearance but not to injure the ventilated patient, the suction pressure can be elevated properly. Last, increasing the inspiratory positive airway pressure (IPAP) is a method to improve the secretion clearance efficiency. This research lays a foundation for improving the secretion clearance efficiency of the IL-IE device.
\end{abstract}

\section{Introduction}

Mechanical ventilation is usually used to ventilate patients who cannot breathe adequately on their own [1-3]. Because of the establishment of artificial airway, the secretion in lungs may be stimulated, and cilium movements may be restrained, which may result in the deposition of secretions in patient's airway $[4,5]$. Coughing is a vital defense mechanism of the airway, and the secretions in the airway can be cleared by peek cough flows (PCFs).

However, as to the ventilated patients, especially in coma, the physiologic function of their epiglottis may be weakened or even lost and the peak cough flows may be severely decreased, and that may seriously depress cough effectiveness [6-8]. Moreover, due to the use of sedatives and muscle relaxants, coughing capacity of ventilated patients may be further diminished [9-11].

Deposition of secretions in a patient's airway may cause a rise in the respiratory resistance, hypoventilation, respiratory failure, and aggravation of the patient's hypoxia and carbon dioxide retention [12-14]. Moreover, secretions blocking airway may easily lead to reproduction of bacteria, which may result in the occurrence or aggravation of the pulmonary infection [15-17]. Last but not least, respiratory complications, due to the airway secretion deposition, are the causes of morbidity and mortality [18-20].

Therefore, in order to maintain airway patency, increase life expectancy, and prolong survival, secretions in ventilated patients must be cleared efficiently and timely [21-24].

Mechanical insufflation-exsufflation (MI-E), as a method for mechanical assisted coughing, can be usually utilized for secretion clearance $[18,25-29]$. Its working principle is that, after a deep inspiration, air in a patient's lungs is expelled out immediately and rapidly by a forced exsufflation. During the exsufflation process, high expiratory flow rate and a high expiratory pressure gradient are generated between the mouth and the alveoli [18]. The PCFs of at least $2.7 \mathrm{~L} / \mathrm{s}$ are required to move secretions up effectively.

Compared with catheter suction technology, the MI-E technology has many advantages:

(1) it is noninvasive and well tolerated hemodynamically [30]; 
(2) it does not introduce pathogens into the lung parenchyma [31];

(3) it is more effective and efficient, as it can clear secretions from not only the right side but also the left side of the bronchial tree. Moreover, it can generate airflow from as deep as the 5th generation bronchi [31].

CoughAssist (Philips Respironics Inc., Murrysville, PA) is a typical MI-E device, and its clinical effects have been approved $[18,26]$. However, when it is applied, the patient's ongoing mechanical ventilation must be interrupted to attach the device to the patient, which may entail first disconnecting the patient from the ventilator. And that may result in the patient's inhalation parameters and $\mathrm{FiO}_{2}$ significantly differing from those to which he had been titrated while on the ventilator, and the patient does not receive positive endexpiratory pressure (PEEP) at all. Furthermore, it is usually repeatedly disconnected and reconnected from the patient and the ventilator by nurses [31].

Considering the disadvantages of the CoughAssist, Be'eri and Eliezer proposed a new MI-E device, called IL-IE device (Innovent Medical Solutions, Jerusalem, Israel). Through clinical application, it was proved that the device can avoid the traumatic and hemodynamic side-effects of catheter suction, improve the efficiency of secretion clearance, reduce the risk of respiratory complications, save staffs' time, and so on [31].

In this paper, to illustrate the working characteristics of the IL-IE device and improve its secretion clearance efficiency, a mathematical model of the ventilation system with an IL-IE device is set up.

Moreover, to verify the mathematical model and avoid the injury to real lungs, a prototype ventilation system of a lung simulator is proposed. On the basis of experimental and simulation study on the prototype system, its dynamic characteristics can be gotten and analyzed.

Last, influences of the key parameters of the ventilator system on the peak exsufflation flow are studied.

\section{Introduction of the IL-IE Device and a Ventilation System with the Device}

2.1. Introduction of the IL-IE Device. According to the working principle of the IL-IE device, its structure diagram can be illustrated in Figure 1. It comprises a controller, a setting unit, a monitor, a ventilator connecting port, a bump, solenoid valves, a pneumatically operated membrane valve, a flow sensor, and a pressure sensor.

The pump can generate compressed air and vacuum simultaneously, the compressed air is used to control the pneumatically operated membrane valve, and the vacuum is utilized for air suction from a ventilated patient's lungs. The pneumatically operated membrane valve is used to connect/ disconnect a ventilator or the pump with a ventilated patient. The flow sensor and pressure sensor are to detect the airflow and pressure in the airway.

The setting unit and monitor are used to set and monitor the working states of the IL-IE device. Based on the signal of the flow sensor and pressure sensor, the controller can judge

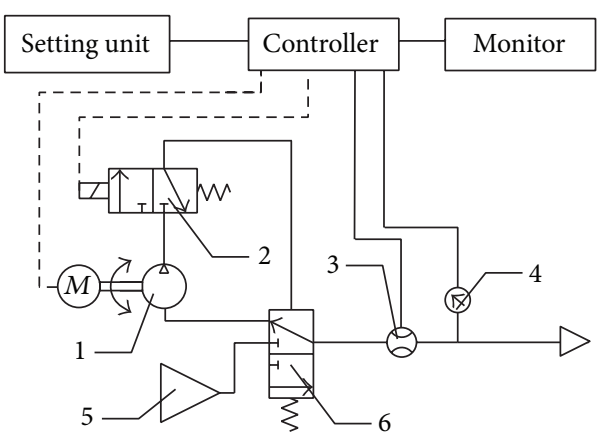

FIGURE 1: Structure diagram of the IL-IE device: 1: pump, 2: solenoid valve, 3: flow sensor, 4: pressure sensor, 5: ventilator connecting port, and 6: pneumatically operated membrane valve.

the time to perform MI-E treatment and control the working states of the pump and the solenoid valve accordingly.

According to [23], the working principle of the IL-IE device is that the device can be connected in-line with the patient's ventilation circuit and endotracheal (ET) tube via a disposable pneumatically operated membrane valve. The device performs MI-E treatments by initiating a sudden suction exsufflation immediately after the ventilator has completed an inspiration, in the following manner. The device monitors the pressure and airflow in the airway, identifies the onset of exhalation, commences high-flow suction at that time, and continues the suction until exsufflation airflow starts approaching zero. Throughout the duration of exsufflation, the membrane valve is activated, closing off the ventilation circuit so that the ventilator itself is not exposed to the exsufflation suction force at all. When exsufflation has terminated and the membrane valve deactivates, reexpose the ventilator to the patient and allow ongoing ventilation to continue uninterruptedly. A single treatment comprises several MI-E cycles in a row (typically 6). After the treatment, secretions which may have migrated up into the ET tube can be removed by performing shallow suction (confined to the ET tube) with an in-line suction catheter, if needed. The device can be programmed to perform MI-E treatments automatically at regular intervals (such as every 15 minutes) in an ongoing fashion and/or can be activated by a button pushed by the nurse or even by the patient, whenever desired. The system can work with both invasive ET tube ventilation and noninvasive facemask ventilation [31].

\subsection{Introduction of a Ventilation System with the IL-IE Device.} A simplified mechanical ventilation system with the IL-IE device, as illustrated in Figure 2(a), is composed of a human lung, some tubes, a ventilator, and an IL-IE device.

According to the main functions of ventilator and the ILIE device, they can be considered as an air compressor and a vacuum pump, respectively.

In this simplified system, the respiratory resistances result from friction loss of the flexible tubes and the respiratory system (including respiratory airway and lung). Therefore, the tubes and the respiratory system of a comatose patient can be equivalent to two combinations of a throttle and 


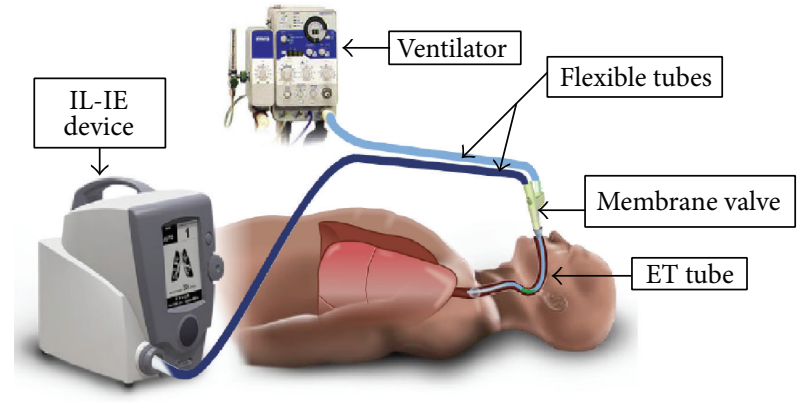

(a) Simplified mechanical ventilation system

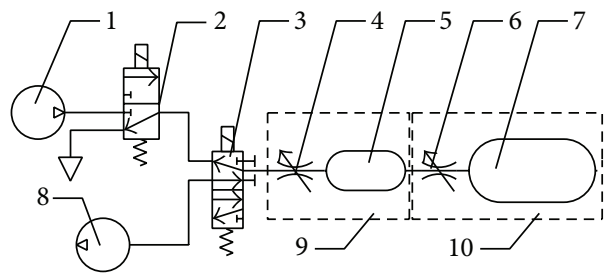

(b) Equivalent pneumatic system

FIGURE 2: Structures of the ventilation system and equivalent pneumatic system: 1: compressor, 2 : solenoid valve $A$, 3: solenoid valve $B$, 4: throttle $A$, 5: container $A, 6$ : throttle $B$, 7: container $B$, 8: vacuum pump, 9; combination $A$, and 10; combination $B$.

a volume variable container, and then the total resistances are represented by the friction losses of the two equivalent throttles.

Because the lengths of the inspiration circuit and the expiration circuit are almost fixed, the structure parameters of the two equivalent combinations, which affect the respiratory resistance, are just their effective areas $\left(A_{t}, A_{r}\right)$ of the two equivalent throttles.

As the pressure of ventilation system is almost $-40 \mathrm{~cm}$ $\mathrm{H}_{2} \mathrm{O} \sim 40 \mathrm{~cm} \mathrm{H}_{2} \mathrm{O}$, compliances of the tubes can be neglected [32-34].

Therefore, the simplified mechanical ventilation system can be regarded as a pure pneumatic system, as shown in Figure 2(b). The compressor, the vacuum pump, combination $A$, and combination $B$ represent the ventilator, the IL-IE device, the flexible tube, and the respiratory system, respectively.

\section{Simulation and Experimental Study on the Mechanical Ventilation System}

\subsection{Modeling of Mechanical Ventilation System}

3.1.1. Flow Equation of the Lung Simulator. When air flows through throttle, its mass flow can be calculated by the equation when air flows through the LAVAL nozzle. As the pressure of the studied ventilation system is about $-40 \mathrm{~cm} \mathrm{H}_{2} \mathrm{O} \sim 40 \mathrm{~cm} \mathrm{H}_{2} \mathrm{O}$, therefore, $p_{d} / p_{u}$ is always bigger than $b(0.528)$; then, the mass flow equation of each throttle in the ventilation system can be obtained as follows:

$$
q=\frac{n_{f} A p_{u}}{\sqrt{\theta}} \sqrt{\frac{2 \kappa}{\kappa-1} \frac{1}{R}\left[\left(\frac{p_{d}}{p_{u}}\right)^{2 / \kappa}-\left(\frac{p_{d}}{p_{u}}\right)^{(\kappa+1) / k}\right]},
$$

where $n_{f}$ is flow coefficient; it is 1 when air flows into a chamber. Inversely, it is -1 when air exhausts from a chamber.

In the standard reference atmosphere state, the volume flow of air can be calculated by the following equation:

$$
Q_{v}=\frac{n_{f} A p_{u}}{\rho_{a} \sqrt{\theta}} \sqrt{\frac{2 \kappa}{\kappa-1} \frac{1}{R}\left[\left(\frac{p_{d}}{p_{u}}\right)^{2 / \kappa}-\left(\frac{p_{d}}{p_{u}}\right)^{(\kappa+1) / k}\right]}
$$

3.1.2. Pressure Equation. The ventilation system can be considered as an open thermodynamic system, and its working can be regarded as an isothermal process. The pressure in the containers in the system can be calculated by the differential expression of Clapeyron equation $(P V=m R \theta)$, which can be given as

$$
\begin{gathered}
\frac{d p}{d t}=\frac{1}{V} R \theta q-m R \theta \frac{1}{V^{2}} \frac{d V}{d t}, \\
\frac{d p}{d t}=\frac{R \theta q V}{V^{2}+C m R \theta} .
\end{gathered}
$$

In this study, the ventilation model is BiPAP and timetriggered. Therefore, in a normal ventilation cycle, the output pressure of the ventilator can be given as

$$
p_{v}= \begin{cases}p_{\text {epap }}+\frac{p_{\text {ipap }}-p_{\text {epap }}}{t_{r}} t, & t \leq t_{r}, \\ p_{\text {ipap }}, & t_{r} \leq t \leq t_{i}, \\ p_{\text {ipap }}-\frac{p_{\text {ipap }}-p_{\text {epap }}}{t_{r}}\left(t-t_{r}\right), & t_{i} \leq t<\left(t_{i}+t_{r}\right), \\ p_{\text {epap }}, & t>\left(t_{i}+t_{r}\right) .\end{cases}
$$

When the secretion should be cleared, the output pressure of the IL-IE device can be defined as the suction pressure $\left(p_{s}\right)$.

3.1.3. Volume Equation. According to the definition of compliance $C$, the compliance $C$ of containers $A$ and $B$ can be described as [35]

$$
\begin{aligned}
& C_{A}=\frac{d V_{A}}{d p_{A}}, \\
& C_{B}=\frac{d V_{B}}{d p_{B}} .
\end{aligned}
$$

Then, the volume of containers $A$ and $B$ can be calculated by the following formulas:

$$
\begin{aligned}
& d V_{A}=C_{A} d p_{A}, \\
& d V_{B}=C_{B} d p_{B} .
\end{aligned}
$$




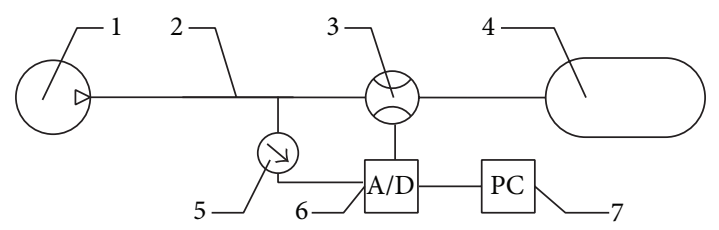

FIGURE 3: Configuration of experimental apparatus: 1: ventilator, 2: tube, 3: flow sensor, 4: lung simulator, 5: pressure sensor, 6: data acquisition card, and 7: computer.

\subsection{Validation of the Mathematical Model}

3.2.1. Experimental Apparatus. As in the above discussion, when the suction pressure of the IL-IE device is set the same as the expiatory positive airway pressure (EPAP), the exsufflation process of the IL-IE device is equal to a normal expiration process of a ventilator. Therefore, the exsufflation process can be considered as a special expiration process of the ventilation system.

To verify the mathematical model and avoid the injury to real lungs, an experimental ventilation system of a lung simulator is proposed, as shown in Figure 3, which consists of a BiPAP ventilator by Philips Respironics, a tube, an Air Power Meter (combines a flow sensor and a pressure sensor) by Tokyo Meter, a lung simulator by VADI, a data acquisition card by Advantech, and a computer by Lenovo. The adopted Air Power Meter (APM-450) can measure the flow, pressure, and temperature of air simultaneously. The uncertainty of the pressure, flow, and temperature is $0.1 \%, \pm 1 \%$ F.S., and $0.10 \mathrm{C}$, respectively [36-38].

\subsubsection{Experimental and Simulation Study on the Ventilation} System. The values of the ventilator settings, including inspiratory positive airway pressure (IPAP), EPAP, breaths per minute (BPM), inspiratory time $\left(T_{i}\right)$, and rise time $\left(T_{r}\right)$ of pressure, are set at $22 \mathrm{~cm} \mathrm{H}_{2} \mathrm{O}, 4 \mathrm{~cm} \mathrm{H}_{2} \mathrm{O}, 20,1.2 \mathrm{~s}$, and $0.3 \mathrm{~s}$, respectively. The diameter of the tube is $22 \mathrm{~mm}$, the inlet diameter of lung simulator is $3.2 \mathrm{~mm}$, and, therefore, the effective areas of the equivalent throttles $A$ and $B$ are $380 \mathrm{~mm}^{2}$ and $8 \mathrm{~mm}^{2}$.

The fluctuation amplitude of airflow and pressure is so high and the frequency is so high that wavelet filter technology was adopted in this study. Through the experiment, it can be calculated that the compliance $(C)$ of the lung simulator is about $5 \mathrm{~mL} / \mathrm{cm} \mathrm{H}_{2} \mathrm{O}$.

The initial values of the parameters in the simulation study are the same as the values in the experimental study. The software Matlab/simulink is used for simulation.

The experimental pressure $\left(p_{t}\right)$ in the tube, the simulation pressure $\left(p_{t}\right)$ in the tube, and the simulation pressure $\left(p_{l}\right)$ in the lung simulator are shown in Figure 4. The airflows of the respiratory system, which are obtained by experimentation and simulation, are shown in Figure 5.

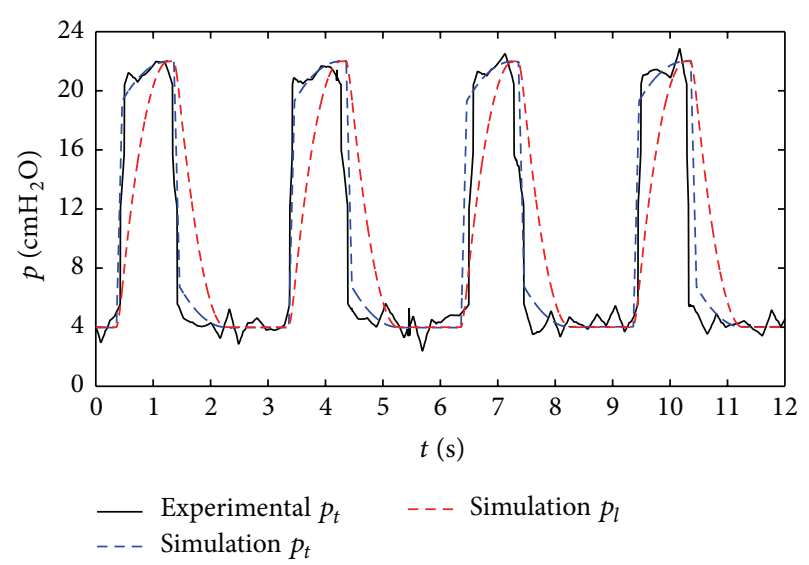

FIgURE 4: Curve and fitted curve of air pressure in tube.

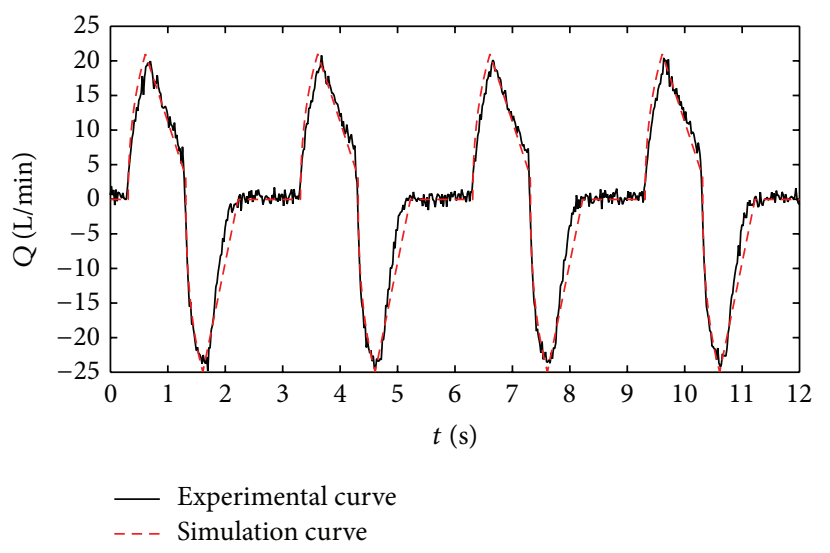

FIGURE 5: Curve of airflow in the system.

From Figures 4 and 5, it can be gotten that

(1) as the average IPAP and EPAP, in the report of the ventilator, are $21.3 \mathrm{~cm} \mathrm{H}_{2} \mathrm{O}$ and $3.9 \mathrm{~cm} \mathrm{H}_{2} \mathrm{O}$, respectively, hence, the measured data are consistent with the ventilator report, and the experiment results are authentic and reliable;

(2) the simulation results have a good consistency with the experimental results, and this verifies the mathematical model above;

(3) as can be seen, the air pressure in the lung simulator always lags behind the output pressure of the ventilator. The main reason is that the respiratory resistance and compliance block the increasing and decreasing of the air pressure in the lung simulator.

Therefore, the mathematical model can be used in the study on the ventilation system with the IL-IE device. 


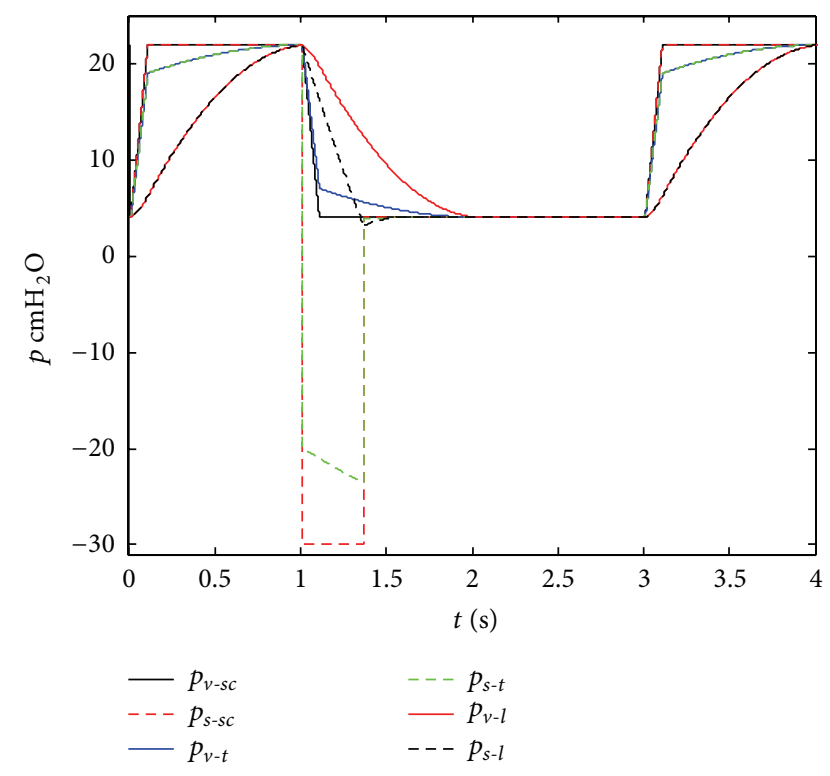

Figure 6: Pressure dynamics of the ventilation system.

\section{Study on the Dynamics of the Ventilation System with the IL-IE Device}

4.1. Dynamics of the Ventilation System. As the compliance of the ventilated lung is set at $50 \mathrm{~mL} / \mathrm{cm} \mathrm{H}_{2} \mathrm{O}$, the inner diameters of the tube and the endotracheal intubation are set at $10 \mathrm{~mm}$ and $7 \mathrm{~mm}$. The IPAP, EPAP, and suction pressure are set at $4 \mathrm{~cm} \mathrm{H}_{2} \mathrm{O}, 22 \mathrm{~cm} \mathrm{H}_{2} \mathrm{O}$, and $-30 \mathrm{~cm} \mathrm{H}_{2} \mathrm{O}$, respectively. When exsufflation flow is less than $2.7 \mathrm{~L} / \mathrm{s}$, the exsufflation process is terminated.

The curves of six pressures (namely, the output pressure $\left(p_{v-s c}\right)$ of the ventilator in the ventilation process, the output pressure $\left(p_{s-s c}\right)$ of the IL-IE device in the secretion clearance process, the pressure $\left(p_{v-t}\right)$ in the tube in the ventilation process, the pressure $\left(p_{s-t}\right)$ in the tube in the secretion clearance process, the pressure $\left(p_{v-l}\right)$ in the ventilated lung in the ventilation process, and the pressure $\left(p_{s-l}\right)$ in the ventilated lung in the secretion clearance process) are shown in Figure 6. The airflow $\left(Q_{v-l}\right)$ of the ventilated lung in the ventilation process and the airflow $\left(Q_{s-l}\right)$ of the ventilated lung in the secretion clearance process are shown in Figure 7.

As illustrated in Figures 6 and 7, the dynamic characteristics of the system during secretion clearance process can be seen.

Due to the respiratory resistance and the compliance, with a growth or a descent in the pressure in the tube, the pressure in the ventilated lung ascends or declines accordingly.

The pressure in the ventilated lung declines faster in the secretion clearance process than in the expiration process. At the end of the exsufflation process, the pressure in the ventilated lung is a little lower than the EPAP, which may harm the patient's respiratory system.

After the exsufflation process, to maintain the EPAP of the ventilation system, the ventilator continues to transfer air to

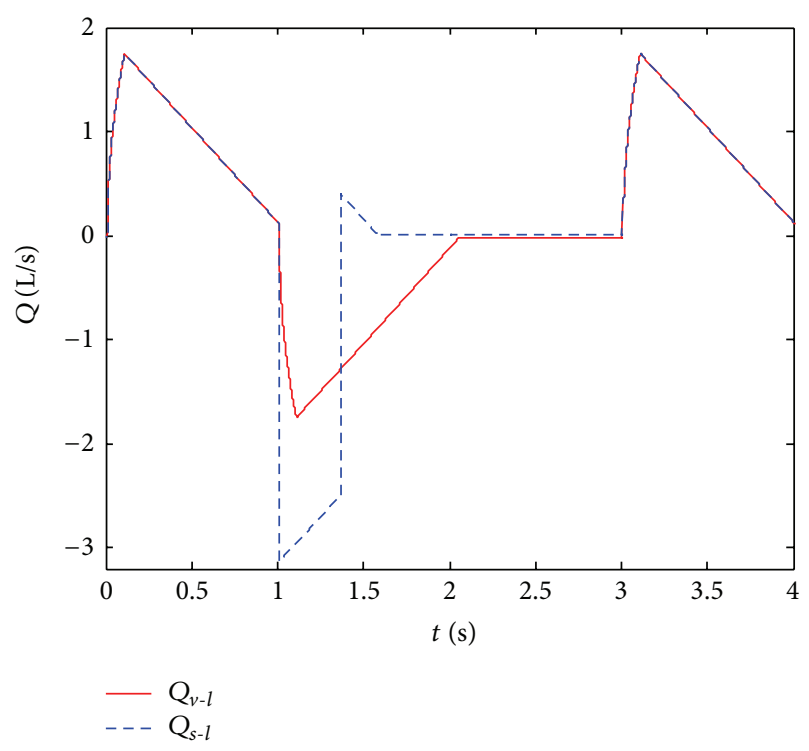

FIGURE 7: Flow dynamics of the ventilated lung.

the ventilated lung, and then the pressures in the tube and the lung start to increase to the EPAP.

4.2. Influence of the key Parameters on the Dynamics of the Ventilation System. According to [27], to clear secretions effectively, the peak exsufflation airflow should be larger than $2.7 \mathrm{~L} / \mathrm{s}$. In order to improve the secretion clearance efficiency of the device, influences of some key parameters (such as the settings of the ventilator, the suction pressure, and the respiratory parameters of the ventilation system) on the dynamics of the ventilation system should be studied.

4.2.1. Influence of the Suction Pressure on the Dynamics. The influences of the suction pressure on the dynamic characteristics of the ventilation system are shown in Figures 8, 9 , and 10 .

As illustrated in Figures 8, 9, and 10, it can be seen that

the peak exsufflation airflow is negatively proportional to the suction pressure. When the suction pressure is lower than $-35 \mathrm{~cm} \mathrm{H}_{2} \mathrm{O}$, the minimum pressure in the ventilated lung increases proportionally with a growth in the suction pressure. However, when the suction pressure is higher than $-35 \mathrm{~cm} \mathrm{H}_{2} \mathrm{O}$, the minimum pressure in the ventilated lung may be higher than the EPAP.

Therefore, decreasing the suction pressure can improve the peak exsufflation airflow. But if the suction pressure is set too low, the minimum pressure in the lung may get lower than the EPAP, and that may injure the patient's respiratory system.

4.2.2. Influences of the Effective Area of the Respiratory Airway on the Dynamics. The influences of the effective area $\left(A_{r}\right)$ of the respiratory airway on the dynamics are depicted in Figures 11, 12, and 13.

As shown in Figures 11, 12, and 13, with a rise in the effective area $A_{r}$, the peak exsufflation airflow of the ventilated lung may ascend. When the effective area $A_{r}$ is bigger 


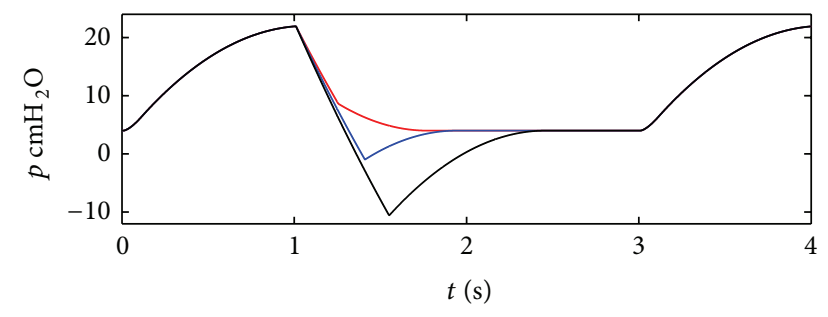

$-p_{s}=-30 \quad-p_{s}=-50$

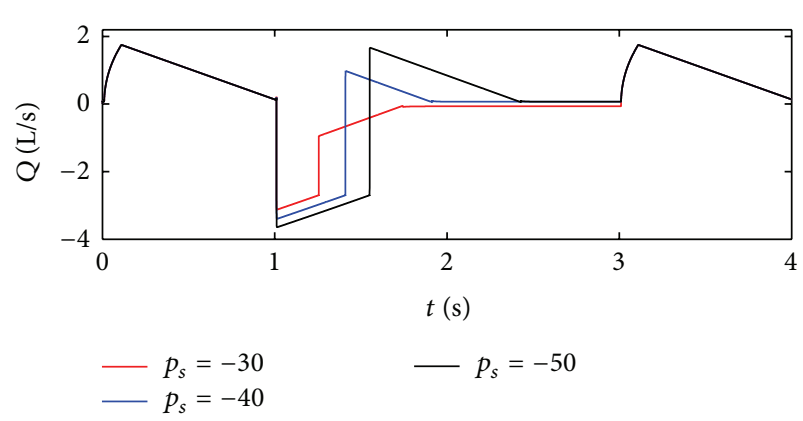

FIGURE 8: Influences of the suction pressure on the dynamics.

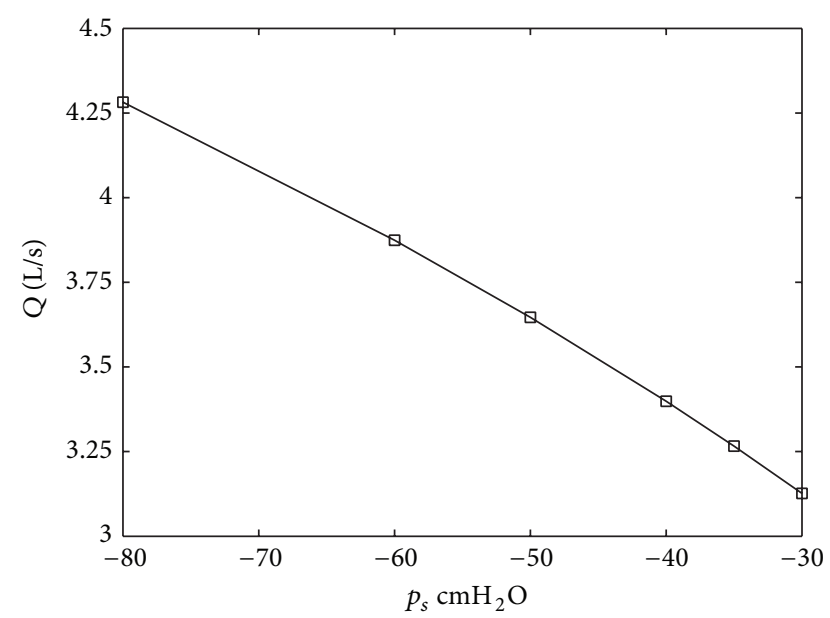

FIGURE 9: Relationship between the peak exsufflation airflow and the suction pressure.

than $40 \mathrm{~mm}^{2}$, the minimum pressure in the ventilated lung may decrease with a rise in the effective area $A_{r}$. However, the effective area $A_{r}$ is smaller than $40 \mathrm{~mm}^{2}$; the minimum pressure in the ventilated lung may be higher than the EPAP.

Therefore, if the effective area $A_{r}$ gets too small, the peak exsufflation airflow may not reach $2.7 \mathrm{~L} / \mathrm{s}$. However, if the effective area $A_{r}$ is too large, the minimum pressure in the lung may drop substantially, which may impair the patient's respiratory system.

4.2.3. Influences of the Respiratory Compliance on the Dynam$i c s$. The influences of the respiratory compliance $(C)$ on the dynamics are depicted in Figures 14 and 15.

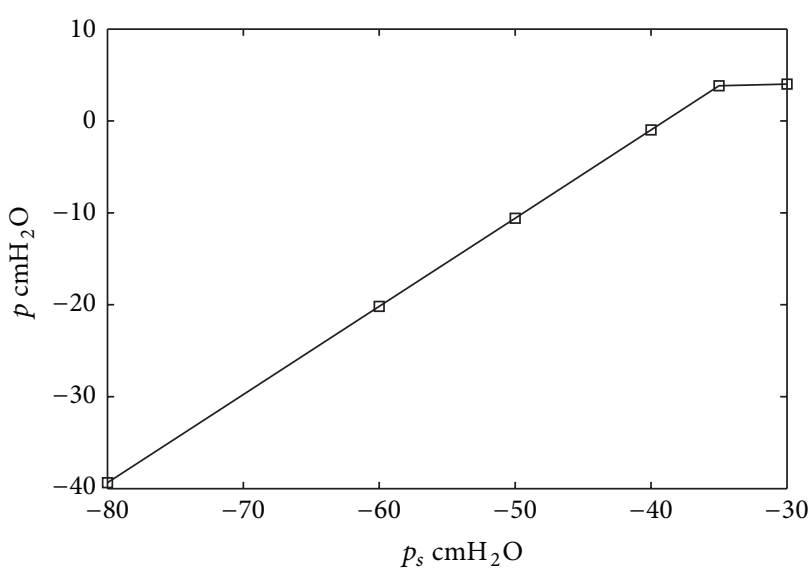

FIGURE 10: Relationship between the minimum pressure in the lung and the suction pressure.
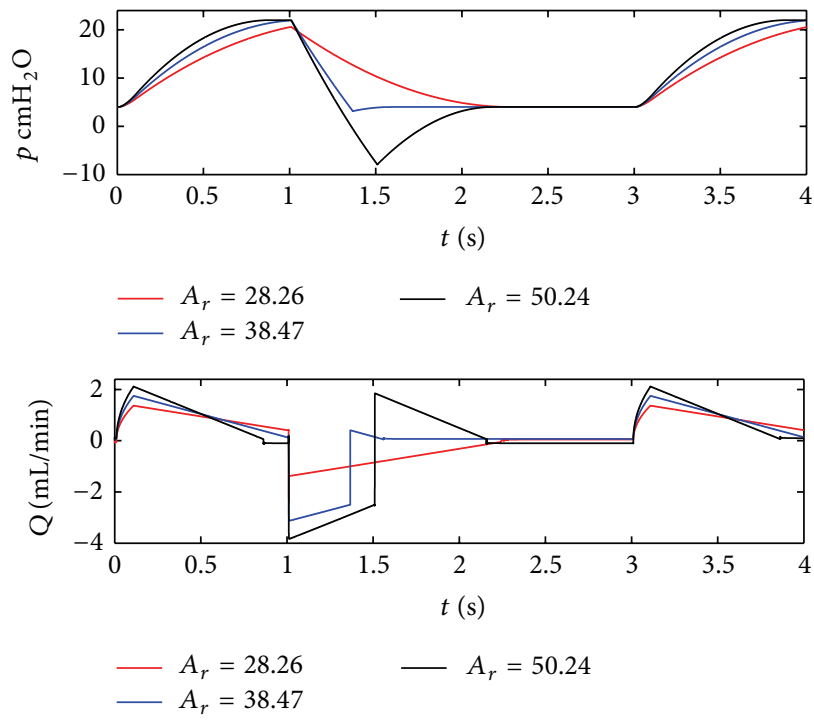

FIGURE 11: Influences of the effective area of the respiratory airway on the dynamics.

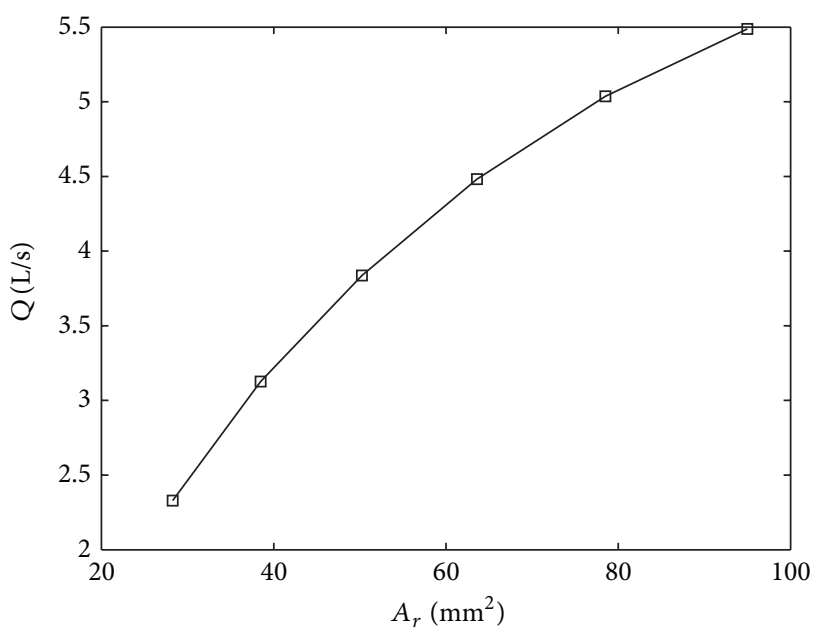

FIGURE 12: Relationship between the peak exsufflation airflow and the effective area $A_{r}$. 


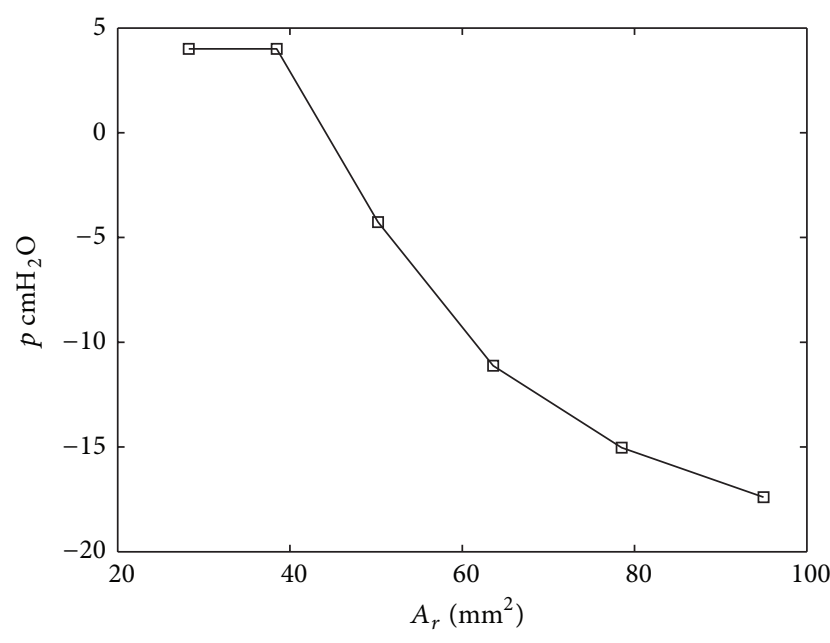

FIGURE 13: Relationship between the minimum pressure in the lung and the effective area $A_{r}$.
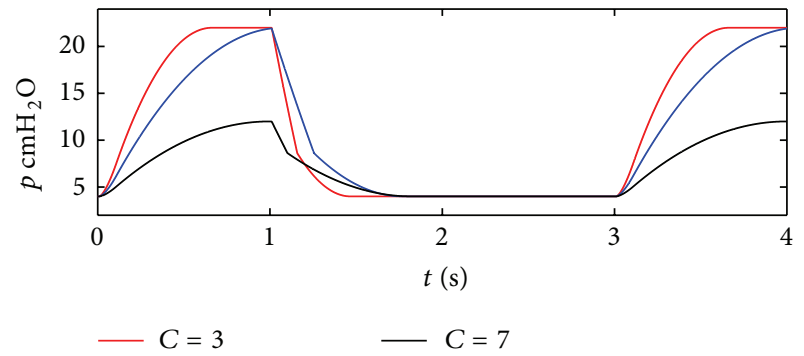

$$
-C=5
$$

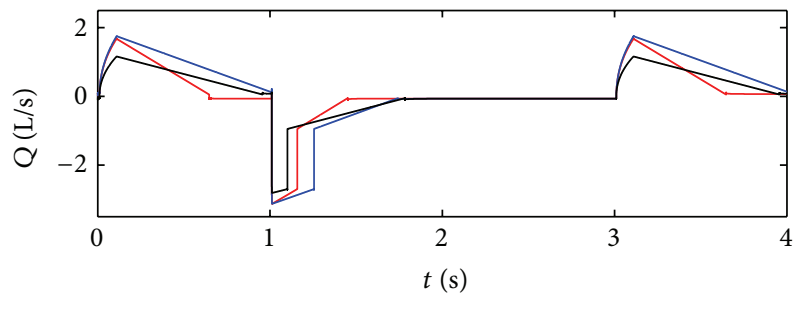

$\begin{aligned} C & =3 \\ -C & =5\end{aligned}$

FIGURE 14: Influences of the respiratory compliance on the dynamics.

It can be seen that the minimum pressure in the lung is hardly influenced by the respiratory compliance. However, when the respiratory compliance is bigger than $5 \mathrm{~mL} / \mathrm{cm} \mathrm{H}_{2} \mathrm{O}$, the peak exsufflation airflow descends with an increase in the respiratory compliance. When the respiratory compliance is smaller than $5 \mathrm{~mL} / \mathrm{cm} \mathrm{H}_{2} \mathrm{O}$, the peak exsufflation airflow almost remains the same.

Therefore, with the deposition of the secretion in the respiratory airway, its effective area may be narrowed, and then the peak exsufflation airflow may be reduced. With an increase in the respiratory compliance, the peak exsufflation airflow may be reduced. To ensure the secretion clearance efficiency, the suction pressure must be elevated properly.

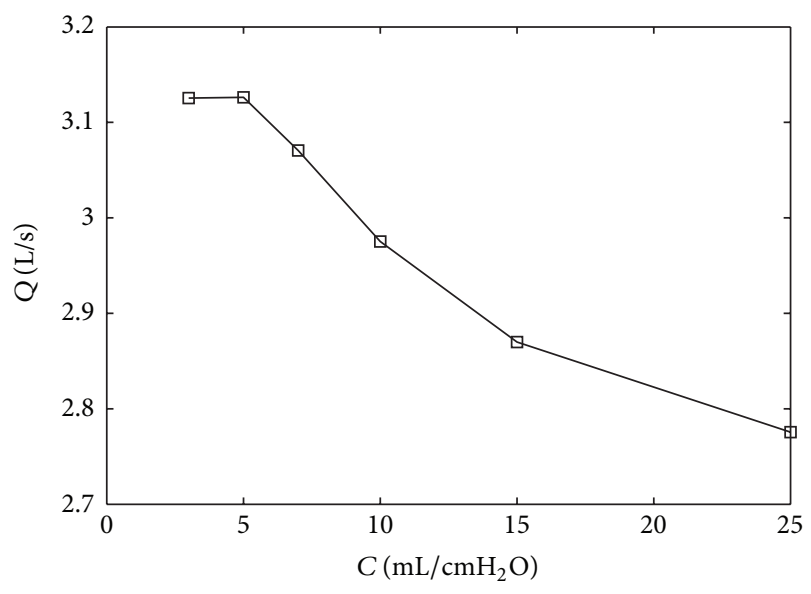

FIGURE 15: Relationship between the peak exsufflation airflow and the respiratory compliance.
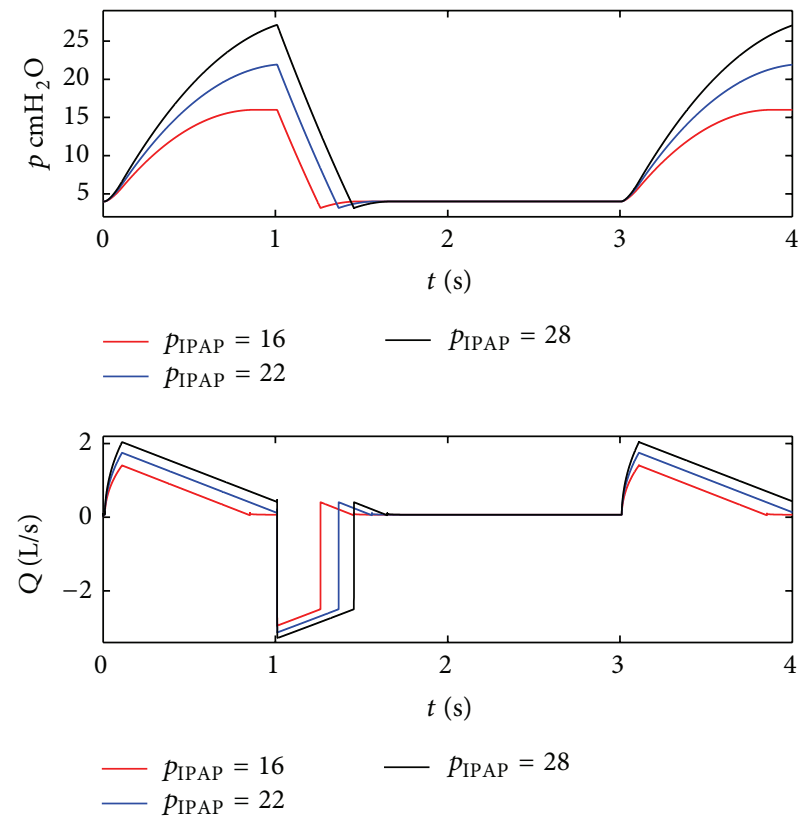

FIGURE 16: Influences of the IPAP on the dynamics.

4.2.4. Influences of the Ventilator Settings on the Dynamics. The influences of the IPAP and EPAP on the dynamics are shown in Figures 16 and 17.

From Figures 16 and 17, it can be seen that

increasing the IPAP can improve the peak exsufflation airflow and prolong the exsufflation duration. However, the exsufflation airflow dynamics are hardly influenced by the EPAP.

Therefore, increasing the IPAP is a method to improve the secretion clearance efficiency, though the IPAP can be adjusted by the IL-IE automatically. 

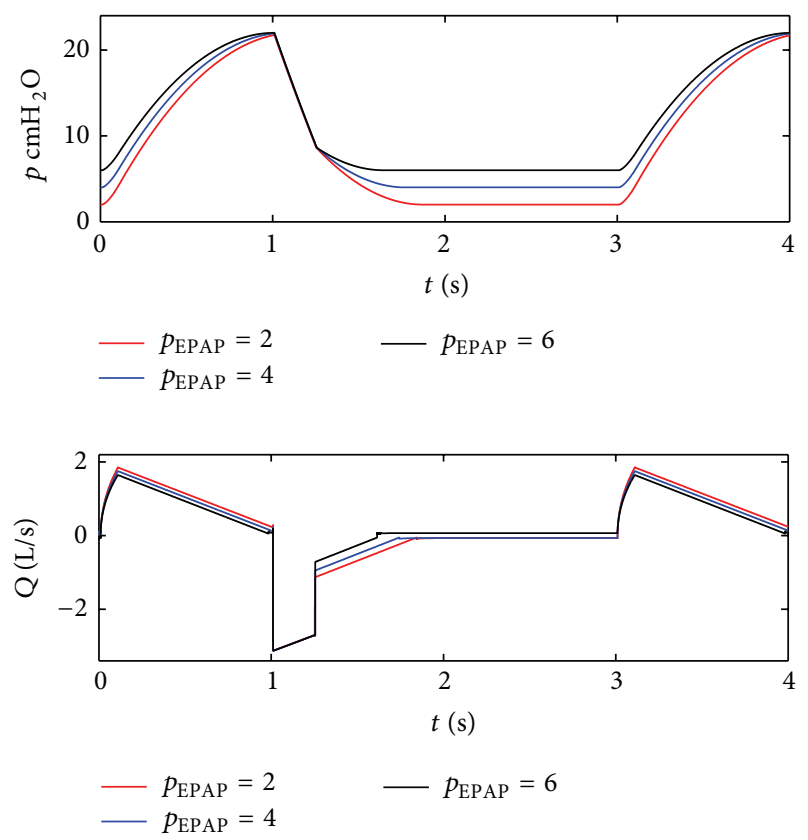

FIGURE 17: Influences of the EPAP on the dynamics.

\section{Conclusions}

In this research, to improve the secretion clearance efficiency and lay a foundation for the optimization of the IL-IE device, the mathematical model of the secretion clearance system is set up. Through the research on the ventilation system, it can be concluded that

(1) the experimental and the simulation results are authentic and reliable, and the mathematical model can be used in the study on the ventilation system with the IL-IE device;

(2) with a decrease in the suction pressure, the peak exsufflation airflow of the ventilated lung may rise proportionally, but the minimum pressure in the ventilated lung may almost descend proportionally. To improve the efficiency of the secretion clearance, the suction pressure can be elevated properly;

(3) with the deposition of secretion or a growth in respiratory compliance, the peak exsufflation airflow may be reduced. To ensure the secretion clearance efficiency, the suction pressure must be elevated appropriately;

(4) increasing the IPAP is a method to improve the secretion clearance efficiency, though the IPAP can be adjusted by the IL-IE.

\section{Nomenclature}

A: Equivalent effective area $\left[\mathrm{m}^{2}\right]$

$b$ : Critical pressure ratio $=0.5283$

C: Respiratory compliance $\left[\mathrm{L} / \mathrm{cmH}_{2} \mathrm{O}\right]$

$d$ : Diameter of equivalent effective area $[\mathrm{m}]$ l: $\quad$ Length, $\mathrm{m}$

$m$ : Mass of air $[\mathrm{kg}]$

$n$ : Coefficient of proportionality

$p$ : Pressure [pa]

$q$ : Air mass flow $[\mathrm{kg} / \mathrm{s}]$

Q: Air volume flow $\left[\mathrm{m}^{3} / \mathrm{s}\right]$

$R:$ Gas constant $=287[\mathrm{~J} /(\mathrm{kg} \cdot \mathrm{K})]$

$t$ : Time [s]

$V:$ Volume $\left[\mathrm{m}^{3}\right]$

$\rho:$ Density $\left[\mathrm{kg} / \mathrm{m}^{3}\right]$

$\kappa:$ Specific heat ratio $=1.4$

$\theta$ : Temperature $[\mathrm{K}]$,

Subscripts

$a: \quad$ The standard reference atmosphere state

$A$ : $\quad$ Equivalent combination $A$

$B$ : $\quad$ Equivalent combination $B$

c: Cycle

d: Downstream side

$e: \quad$ Expiration

$f$ : $\quad$ Flow of air

epap: Expiatory positive airway pressure

$i$ : Inspiration

il-ie: The IL-IE device

ipap: Inspiratory positive airway pressure

$l$ : $\quad$ Lung

$r$ : $\quad$ Pressure rising time

$s: \quad$ Suction process/exsufflation process

$t$ : Tube

$u$ : Upstream side

$v$ : Ventilator or ventilation process.

\section{Conflict of Interests}

The authors declare that there is no conflict of interests regarding the publication of this paper.

\section{Acknowledgment}

The research is funded by Open Foundation of the State Key Laboratory of Fluid Power Transmission and Control.

\section{References}

[1] F. T. Tehrani, "A control system for mechanical ventilation of passive and active subjects," Computer Methods and Programs in Biomedicine, vol. 110, no. 3, pp. 511-518, 2013.

[2] S. P. Pilbeam and J. M. Cairo, Mechanical Ventilation, Physiological and Clinical Application, Mosby Elsevier, St. Louis, Mo, USA, 4th edition, 2006.

[3] R. L. Chatburn, "Classification of ventilator modes: update and proposal for implementation," Respiratory Care, vol. 52, no. 3, pp. 301-323, 2007.

[4] V. Gerber and N. E. Robinson, "Airway secretions and mucociliary function," Equine Respiratory Medicine and Surgery, pp. 5569, 2007. 
[5] L. Rose and G. Hanlon, "Ventilation and oxygenation management," in ACCCN's Critical Care Nursing, p. 381, 2011.

[6] F. Glynn and J. E. Fenton, "Diagnosis and management of supraglottitis (epiglottitis)," Current Infectious Disease Reports, vol. 10, no. 3, pp. 200-204, 2008.

[7] H. Katori and M. Tsukuda, "Acute epiglottitis: analysis of factors associated with airway intervention," Journal of Laryngology \& Otology, vol. 119, no. 12, pp. 967-972, 2005.

[8] L.-. Guldfred, D. Lyhne, and B. C. Becker, "Acute epiglottitis: epidemiology, clinical presentation, management and outcome," Journal of Laryngology and Otology, vol. 122, no. 8, pp. 818-823, 2008.

[9] C. Newmarch, "Caring for the mechanically ventilated patient: part two," Nursing Standard, vol. 20, no. 18, pp. 55-66, 2006.

[10] P. Feltracco, G. Falasco, S. Barbieri, M. Milevoj, E. Serra, and C. Ori, "Anesthetic considerations for nontransplant procedures in lung transplant patients," Journal of Clinical Anesthesia, vol. 23, no. 6, pp. 508-516, 2011.

[11] A. Sinha and F. Carli, "The role of regional anaesthesia in patient outcome: thoracic and abdominal surgeries," Techniques in Regional Anesthesia and Pain Management, vol. 12, no. 4, pp. 183-193, 2008.

[12] S. M. Maggiore, F. Lellouche, J. Pigeot et al., "Prevention of endotracheal suctioning-induced alveolar derecruitment in acute lung injury," The American Journal of Respiratory and Critical Care Medicine, vol. 167, no. 9, pp. 1215-1224, 2003.

[13] T. Dyhr, J. Bonde, and A. Larsson, "Lung recruitment manoeuvres are effective in regaining lung volume and oxygenation after open endotracheal suctioning in acute respiratory distress syndrome," Critical Care, vol. 7, no. 1, pp. 55-62, 2003.

[14] U. Munnur, V. D. Bandi, and M. A. Gropper, "Airway management and mechanical ventilation in pregnancy," in Pulmonary Problems in Pregnancy, K. Rosene-Montella and G. Bourjeily, Eds., Respiratory Medicine, pp. 385-403, 2009.

[15] M. Tsoumakidou and N. M. Siafakas, "Novel insights into the aetiology and pathophysiology of increased airway inflammation during COPD exacerbations.," Respiratory Research, vol. 7, article 80, 2006.

[16] B. M. Morrissey, "Pathogenesis of Bronchiectasis," Clinics in Chest Medicine, vol. 28, no. 2, pp. 289-296, 2007.

[17] D. Huh, H. Fujioka, Y. Tung et al., "Acoustically detectable cellular-level lung injury induced by fluid mechanical stresses in microfluidic airway systems," Proceedings of the National Academy of Sciences of the United States of America, vol. 104, no. 48, pp. 18886-18891, 2007.

[18] J. Sancho, E. Servera, J. Díaz, and J. Marín, "Efficacy of mechanical insufflation-exsufflation in medically stable patients with amyotrophic lateral sclerosis," Chest, vol. 125, no. 4, pp. 14001405, 2004.

[19] B. Fauroux, N. Guillemot, G. Aubertin et al., "Physiologic benefits of mechanical insufflation-exsufflation in children with neuromuscular diseases," Chest, vol. 133, no. 1, pp. 161-168, 2008.

[20] N. Lechtzin, C. M. Wiener, L. Clawson, V. Chaudhry, and G. B. Diette, "Hospitalization in amyotrophic lateral sclerosis: causes, costs, and outcomes," Neurology, vol. 56, no. 6, pp. 753-757, 2001.

[21] R. D. Branson, "Secretion management in the mechanically ventilated patient," Respiratory Care, vol. 52, no. 10, pp. 13281342, 2007.

[22] A. Lucchini, A. Zanella, G. Bellani et al., "Tracheal secretion management in the mechanically ventilated patient: comparison of standard assessment and an acoustic secretion detector," Respiratory Care, vol. 56, no. 5, pp. 596-603, 2011.
[23] M. K. Sontag, A. L. Quittner, A. C. Modi et al., "Lessons learned from a randomized trial of airway secretion clearance techniques in cystic fibrosis," Pediatric Pulmonology, vol. 45, no. 3, pp. 291-300, 2010.

[24] J. S. Flores, F. Â. Teixeira, P. M. E. Rovedder, B. Ziegler, and P. D. T. R. Dalcin, "Adherence to airway clearance therapies by adult cystic fibrosis patients," Respiratory Care, vol. 58, no. 2, pp. 279285, 2013.

[25] D. N. Homnick, "Mechanical insufflation-exsufflation for airway mucus clearance," Respiratory Care, vol. 52, no. 10, pp. 12961305, 2007.

[26] C. Guérin, G. Bourdin, V. Leray et al., "Performance of the coughAssist insufflation-exsufflation device in the presence of an endotracheal tube or tracheostomy tube: a bench study," Respiratory Care, vol. 56, no. 8, pp. 1108-1114, 2011.

[27] J. D. Finder, "Airway clearance modalities in neuromuscular disease," Paediatric Respiratory Reviews, vol. 11, no. 1, pp. 31-34, 2010.

[28] V. Porot and C. Guérin, "Bench assessment of a new insufflation-exsufflation device," Respiratory Care, vol. 58, no. 9, pp. 1536-1540, 2013.

[29] B. Morrow, M. Zampoli, H. van Aswegen et al., "Mechanical insufflation-exsufflation for people with neuromuscular disorders," Cochrane Database of Systematic Reviews, no. 12, Article ID CD010044, 2013.

[30] J. R. Bach, "Pulmonary rehabilitation considerations for Duchenne Muscular Dystrophy: the prolongation of life by respiratory muscle aids," Critical Reviews in Physical and Rehabilitation Medicine, vol. 3, pp. 239-269, 1992.

[31] E. Be'eri, "Automated airway secretion clearance in the ICU by in-line inexsufflation: clinical implications and technology," in Humidification in the Intensive Care Unit, pp. 237-243, Springer, Berlin, Germany, 2012.

[32] R. L. Chatburn, "Computer control of mechanical ventilation," Respiratory Care, vol. 49, no. 5, pp. 507-517, 2004.

[33] J. X. Brunner, History and Principles of Closed-Loop Control Applied to Mechanical Ventilation, 2002.

[34] M. Borrello, "Modeling and control of systems for critical care ventilation," in Proceedings of the American Control Conference, pp. 2166-2180, Portland, Ore, USA, June 2005.

[35] N. Jaimchariyatam, R. A. Dweik, R. Kaw, and L. S. Aboussouan, "Polysomnographic determinants of nocturnal hypercapnia in patients with sleep apnea," Journal of Clinical Sleep Medicine, vol. 9, no. 3, pp. 209-215, 2013.

[36] Y. Shi and M. Cai, "Working characteristics of two kinds of airdriven boosters," Energy Conversion and Management, vol. 52, no. 12, pp. 3399-3407, 2011.

[37] M. Cai, T. Funaki, K. Kawashima, and T. Kagawa, "Development of pneumatic power meter for energy saving," in Proceedings of the Symposium on Fluid Power System at Spring, Tokyo, Japan, 2003.

[38] M. Cai, K. Kawashima, and T. Kagawa, "Power assessment of flowing compressed air," Journal of Fluids Engineering, Transactions of the ASME, vol. 128, no. 2, pp. 402-405, 2006. 


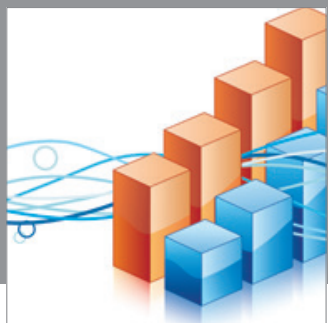

Advances in

Operations Research

mansans

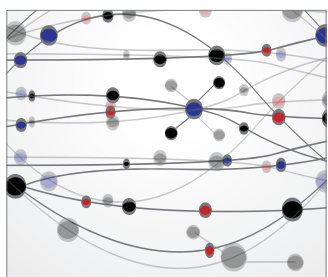

The Scientific World Journal
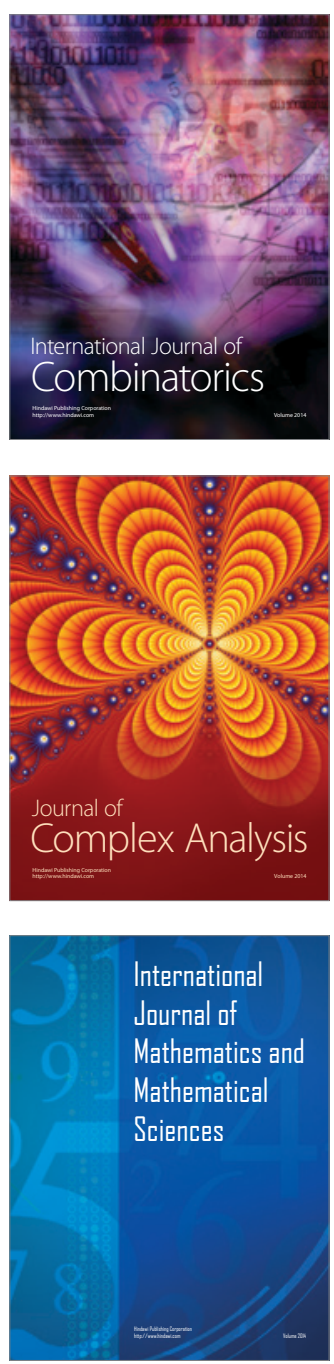
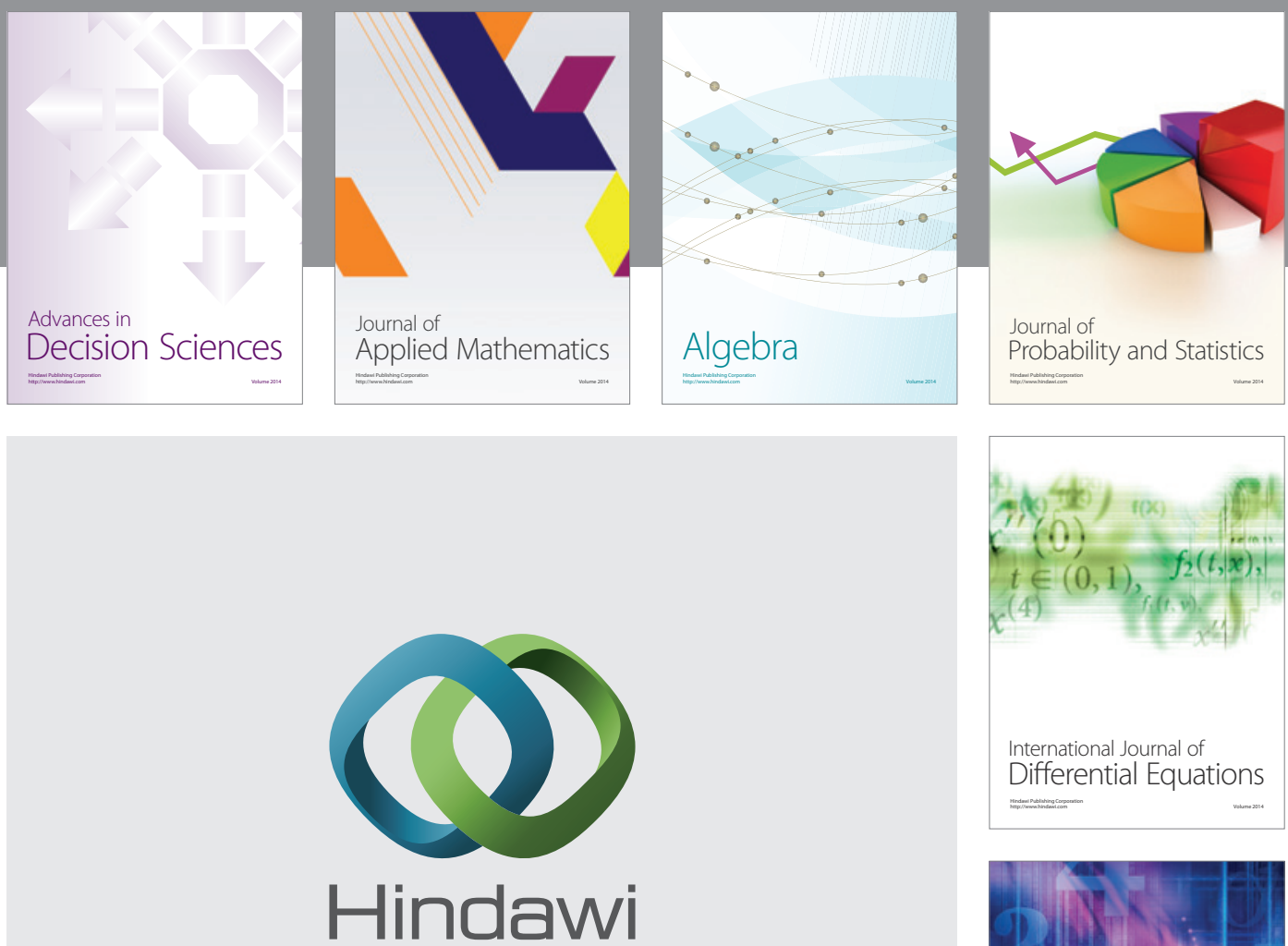

Submit your manuscripts at http://www.hindawi.com
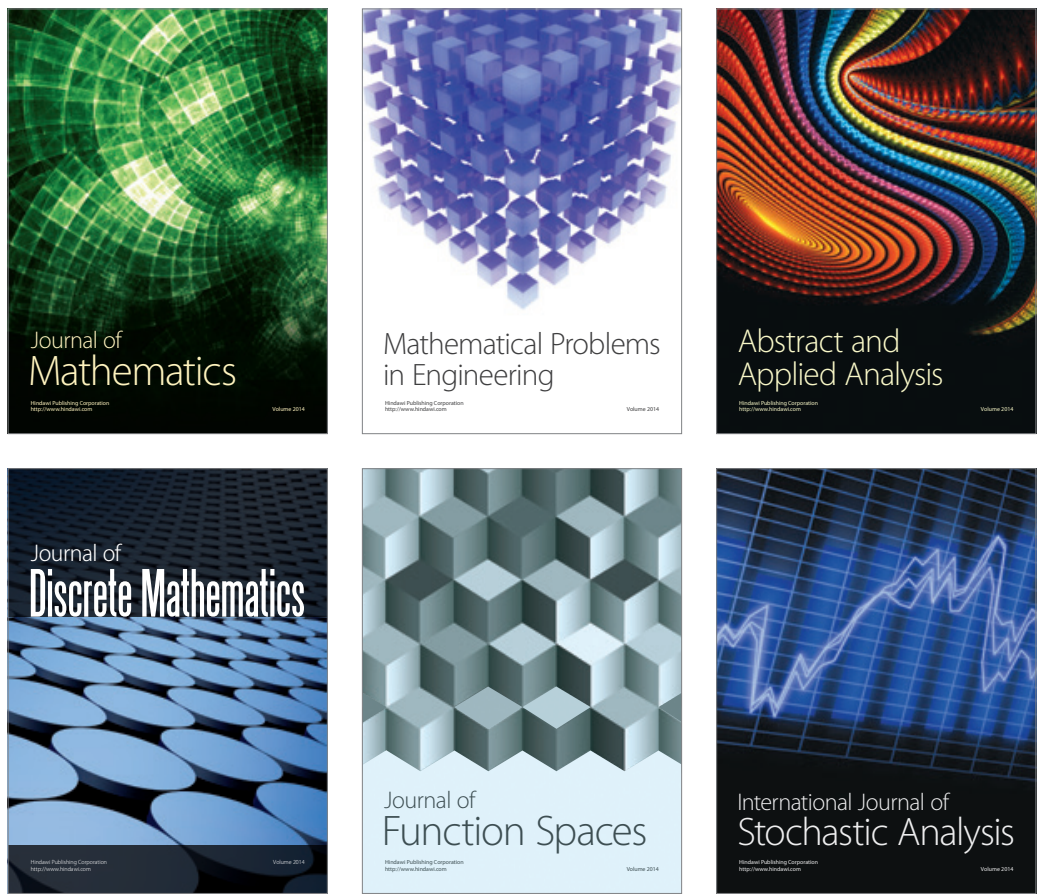

Journal of

Function Spaces

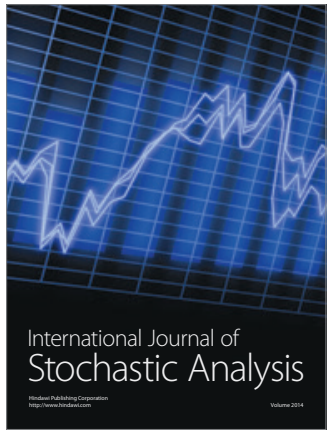

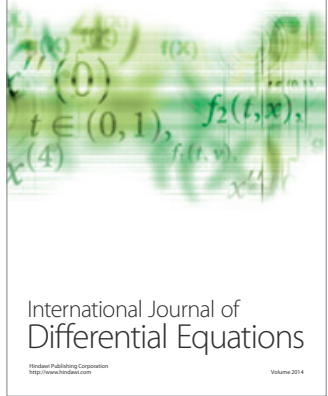
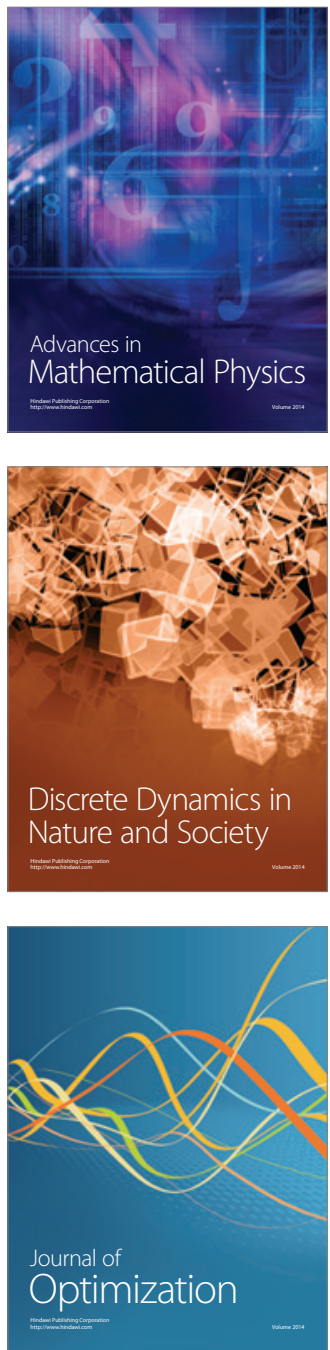